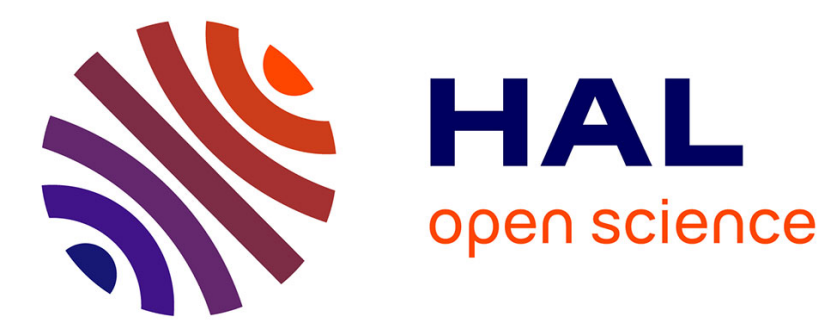

\title{
Easy and efficient selenocyanation of imidazoheterocycles using triselenodicyanide
}

Sébastien Redon, Anne Roly Obah Kosso, Julie Broggi, Patrice Vanelle

\section{To cite this version:}

Sébastien Redon, Anne Roly Obah Kosso, Julie Broggi, Patrice Vanelle. Easy and efficient selenocyanation of imidazoheterocycles using triselenodicyanide. Tetrahedron Letters, 2017, 58 (28), pp.27712773. 10.1016/j.tetlet.2017.06.003 . hal-01665068

\section{HAL Id: hal-01665068 https://hal.science/hal-01665068}

Submitted on 4 Jan 2018

HAL is a multi-disciplinary open access archive for the deposit and dissemination of scientific research documents, whether they are published or not. The documents may come from teaching and research institutions in France or abroad, or from public or private research centers.
L'archive ouverte pluridisciplinaire HAL, est destinée au dépôt et à la diffusion de documents scientifiques de niveau recherche, publiés ou non, émanant des établissements d'enseignement et de recherche français ou étrangers, des laboratoires publics ou privés. 


\title{
Easy and efficient selenocyanation of imidazoheterocycles using triselenodicyanide
}

\author{
Sébastien Redon, ${ }^{*}$ Anne Roly Obah Kosso, Julie Broggi and Patrice Vanelle* \\ Aix Marseille Univ, CNRS, ICR Institut de Chimie Radicalaire, UMR 7273, Equipe Pharmaco-Chimie Radicalaire (LPCR), Faculté de Pharmacie, 27 Bd Jean \\ Moulin CS-30064 13385 Marseille Cedex5, France
}

\section{ARTICLE INFO}

Article history:

Received

Received in revised form

Accepted

Available online

\section{Keywords:}

Selenocyanate

Imidazoheterocycles

Triselenodicyanide

Selenium dioxide

Malononitrile

\section{ABSTRACT}

The regioselective selenocyanation of imidazoheterocycles using triselenodicyanide at room temperature is reported. The electrophilic aromatic substitution of a broad range of substrates is promoted by the triselenodicyanide obtained by oxidative coupling of malononitrile and selenium dioxide, under an air atmosphere. The major advantages of the presented method are an easy set-up, excellent yields, short reaction times, use of odorless and inexpensive reagents and easy purification of the final products.

Interest in the fused bicyclic imidazo[1,2-a]pyridine moiety has been demonstrated in medicinal chemistry, offering a wide range of activities including antibacterial, antifungal, antiinflammatory, antiviral, and antitumor properties. ${ }^{1}$ The biological activities of some remarkable imidazo[1,2-a]-pyridines (such as alpidem, necopidem, miroprofen, saripidem, zolpidem or zolimidine) are chiefly dependent on the nature of the substituents at the C-2 or C-3 positions. Therefore, substantial efforts have been devoted to the development of new methods for the efficient functionalization of this heterocyclic ring. ${ }^{2}$

Moreover, selenocyanate substituted heterocycles have shown interesting activities as antileishmanial agents ${ }^{3}$ and cancer chemopreventive agents. ${ }^{4}$ The selenocyanate functional group has also demonstrated its synthetic usefulness as an air- and moisturestable selenium halide analogue. This groups reacts with a large panel of reagents leading upon decyanation to the corresponding selenolate ${ }^{5}$ (with $\mathrm{NaBH}_{4}$ or base), trifluoromethylselenide ${ }^{6}$ (with Ruppert-Prakash reagent) and unsymmetrical selenide ${ }^{7}$ (by crosscoupling) derivatives. In this sense, new synthetic strategies to inserting the $\mathrm{SeCN}$ group will indubitably be of high value.

Methodologies to introduce the selenocyanate functional group are relatively recent and present the disadvantage of using odorous and air sensitive potassium selenocyanate $(\mathrm{KSeCN})$. Reported procedures, applied to enriched arenes, utilise this reagent as an electrophilic source with $\mathrm{N}$-iodosuccinimide as a catalyst and tert-butyl hydroperoxide as an oxidant, ${ }^{8}$ or as a radical SeCN source with cerium(IV) ammonium nitrate ${ }^{9 \mathrm{a}}$ (or $\mathrm{K}_{2} \mathrm{~S}_{2} \mathrm{O}_{8}{ }^{9 \mathrm{~b}}$ ) as an oxidant. Regarding the imidazoheterocycles,

selenocyanation has been performed with only one substrate (1a) using $\mathrm{KSeCN}$ as a radical nucleophile $\mathrm{e}^{10}$ via visible light photoreduction with eosin $\mathrm{Y}$ in moderate yield $(51 \%)$ or as an electrophilic source with the oxidant $N$-chlorosuccinimide. ${ }^{11}$ In addition to $\mathrm{KSeCN}$, these methods require the use of blue LEDs and tedious column chromatography.

In order to develop a more attractive industrial process, it is of high importance to offer a straightforward, odorless, inexpensive and scalable method. Triselenodicyanide represents an ideal electrophilic source, ${ }^{12}$ especially considering its simple and cheap generation from malononitrile and odorless selenium dioxide. ${ }^{13}$ So far, this reagent has only been employed for the selenocyanation of aniline derivatives. ${ }^{3}$ In a continuation of our research program centered on the medicinal chemistry of nitrogen-containing heterocycles, ${ }^{14}$ we investigated the reactivity of triselenodicyanide in the selenocyanation of various imidazoheterocycles.

We first undertook a detailed optimization study summarized in Table 1. First, triselenodicyanide was prepared by mixing selenium dioxide ( 3 equiv.) and malononitrile (1.5 equiv.) in different solvents for $20 \mathrm{~min}$. Performing these reactions under diluted condition $\left(1.0 \mathrm{~mol} . \mathrm{L}^{-1}\right)$ was necessary to circumvent the problems encountered at higher concentrations, namely insolubility of the substrates, high exothermicity of the reaction and a gas release. ${ }^{15}$ Then, 2-phenylimidazo[1,2- $a$ ]pyridine (1a) was added as a model substrate at room temperature. Solvent evaluation revealed that organic solvents, such as acetone, isopropanol, ethanol, and 1,4-dioxane, gave moderate results with yields ranging from 10 to $60 \%$ (Table 1, entries 1-4).

No reaction occurred with ethyl acetate or dichloromethane (Entries 5-6). DMSO and DMF proved to be the best solvents, with 84\% and $75 \%$ yield, respectively (Entries 7-8). After $30 \mathrm{~min}$ stirring at r.t., 6 volumes of water were added to precipitate the pure selenocyanated product (2a). The proportions of selenium dioxide and malononitrile could be decreased to a 3:1 ratio without a loss of efficiency (Entry 11). Lower amounts led to decreased yields (Entries 9-10). 
Table 1. Optimization of reaction conditions.

\begin{tabular}{|c|c|c|c|c|}
\hline Entry & Solvent & $\begin{array}{c}\mathrm{SeO}_{2} \\
\text { (equiv.) }\end{array}$ & $\begin{array}{c}\text { Malononitrile } \\
\text { (equiv.) }\end{array}$ & $\begin{array}{l}\text { Yield }^{\mathrm{a}} \\
\mathbf{2 a}(\%)\end{array}$ \\
\hline 1 & Acetone & 3 & 1.5 & 60 \\
\hline 2 & Propan-2-ol & 3 & 1.5 & 50 \\
\hline 3 & Ethanol & 3 & 1.5 & 45 \\
\hline 4 & 1,4-Dioxane & 3 & 1.5 & 10 \\
\hline 5 & Ethyl acetate & 3 & 1.5 & n.r. \\
\hline 6 & Dichloromethane & 3 & 1.5 & n.r. \\
\hline 7 & DMSO & 3 & 1.5 & 84 \\
\hline 8 & DMF & 3 & 1.5 & 75 \\
\hline 9 & DMSO & 1 & 0.5 & 32 \\
\hline 10 & DMSO & 2 & 1 & 63 \\
\hline 11 & DMSO & 3 & 1 & 85 \\
\hline
\end{tabular}

Scheme 1. Scope of the selenocyanation of imidazo[1,2-a]heterocycles. ${ }^{\text {a, }}$

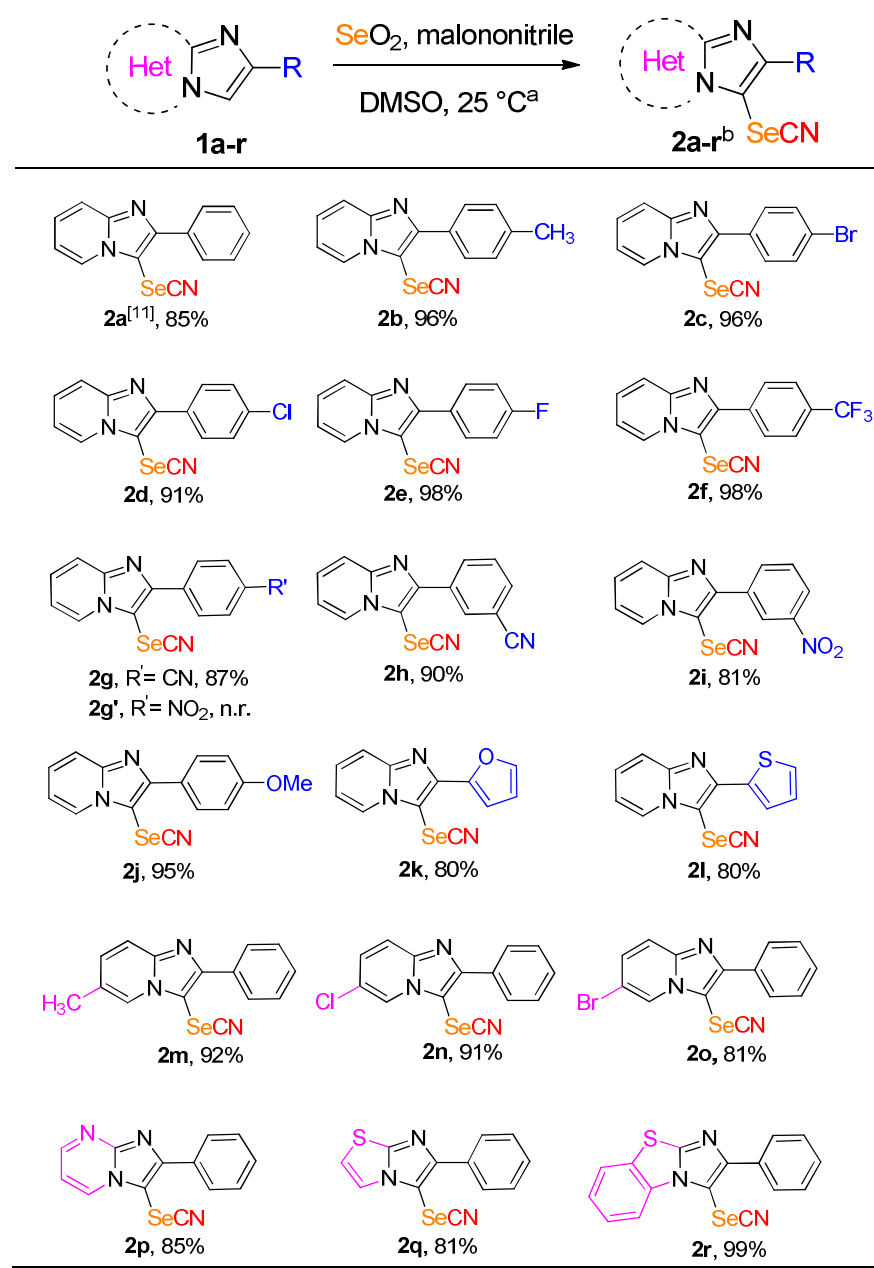

${ }^{\text {a }}$ Reaction conditions: substrate 1a-r $(0.5 \mathrm{mmol})$ was added to a prepared solution of

$\mathrm{SeO}_{2}$ (3 equiv.) and malononitrile (1 equiv.) in DMSO $(0.5 \mathrm{~mL})$ at $25^{\circ} \mathrm{C}$.

The reaction mixture was stirred for 30 min under an air atmosphere.

${ }^{\mathrm{b}}$ Isolated yield. n.r.= no reaction. 
Next, we examined the scope of our selenocyanation method with a large number of variously decorated imidazoheterocycles (Scheme 1). ${ }^{16}$ The electrophilic aromatic substitution proceeded in excellent yields and tolerated numerous functional groups such as methyl (2b, 2m), halogen (2c, 2d, 2e, 2f, 2n, 2o), alkoxy (2j) or nitrile groups (2g, 2h). Both electron-rich and -deficient substituents on the 2-phenyl moiety were well tolerated. The relative positioning of the substituent on the aromatic ring (meta- or para-position) did not affect the efficiency of the reaction. Only one example failed to give the expected selenocyanated 2-(4-nitrophenyl)-imidazo[1,2a]pyridine (2')'), bearing a strongly deactivating $\mathrm{NO}_{2}$ group. Other heterocycles such as 2-furan (2k) or 2-thiophene rings (2l) were compatible with imidazopyridine 3-selenocyanation. Finally, our optimized selenocyanation procedure was successfully extended to other imidazoheterocyclic compounds such as imidazopyrimidine (2p, 85\%), imidazothiazole (2q, 81\%) and imidazobenzothiazole (2r, $99 \%)$.

This methodology was also applicable to a gram-scale synthesis (Scheme 2). The reaction of 2-(phenyl)-imidazo[1,2-a]pyridine (1aa, $8 \mathrm{mmol}$ ) afforded the 2-phenyl-3-selenocyanatoimidazo[1,2-a]pyridine (2b) in $84 \%$ yield. This result demonstrates the practicality of our protocol.

Scheme 2. Gram-scale reaction.

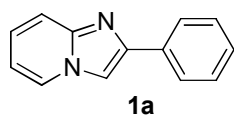

$1.5 \operatorname{grams}(8 \mathrm{mmol})$

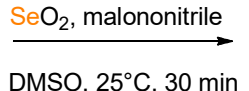

DMSO, $25^{\circ} \mathrm{C}, 30 \mathrm{~min}$

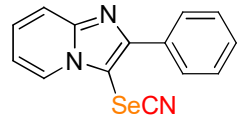

2a, $84 \%$

A one-pot sequence was then tested using commercially available $\alpha$-bromo acetophenone and 2 -aminopyridine as starting materials (Scheme 3). The first step involved the formation of the 2-phenylimidazo[1,2-a]pyridine motif by cyclization in the presence of $\mathrm{K}_{2} \mathrm{CO}_{3}$ to trap the released $\mathrm{HBr} .{ }^{17}$ After reaction completion, followed by ${ }^{1} \mathrm{H} \mathrm{NMR}$, the selenocyanation step on the C-3 position was accomplished using the previously determined conditions. Unfortunately, no precipitation occurred upon the addition of water in this case, so the advantage of the simple filtration process was lost. Purification by column chromatography gave the expected product (2a) in $63 \%$ yield.

Scheme 3. Sequential, one-pot reaction.
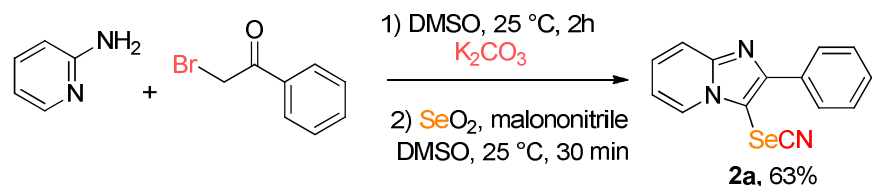

To demonstrate the utility of the selenocyanated substrates, various transformations of the SeCN functional group were examined (Scheme 4). The imidazopyridine (2a) could be reduced with $\mathrm{NaBH}_{4}$ then oxidized at air to form a diselenide bridge in the dimeric form (3a) in $79 \%$ yield. The $\mathrm{SeCN}$ group could also be easily converted into a $\mathrm{Se}_{-} \mathrm{CH}_{3}$ group (3b) by a one-pot reduction and alkylation with methyliodide. A Se-aryl derivative (3c) was obtained in $91 \%$ yield by addition of a Grignard reagent. The $\mathrm{SeCF}_{3} \mathrm{counterpart}^{(3 \mathbf{d})}$ was obtained in $44 \%$ yield by addition of the Ruppert-Prakash reagent. Finally, the $\mathrm{SeO}_{2} \mathrm{H}$ group, an attractive bioisotere of carboxy groups, was introduced in moderate yield $(3 \mathbf{e}, 55 \%)$ by the addition of sulfuryl chloride followed by hydrochloric acid.

Scheme 4. Transformations of the SeCN functional group in $\mathbf{2 a}$.

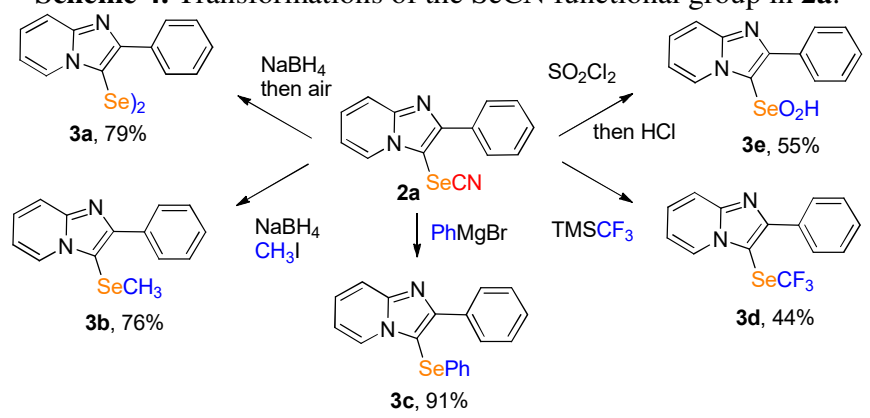

In summary, we have developed an efficient methodology for the regioselective selenocyanation of imidazo[1,2-a]pyridine derivatives at room temperature with a high degree of functional group tolerance. The method is characterized by the use of odorless and inexpensive starting materials, an ease of purification (filtration), and excellent yields. The scope was extended to imidazo[2,1$b]$ thiazole and 2-phenylbenzo[b]imidazo[2,1-b]thiazole derivatives. This method represents a robust protocol for the functionalization of a new class of medicinally important heterocycles.

\section{Acknowledgments}

Aix-Marseille Université and the Centre National de la Recherche Scientifique (CNRS) are gratefully acknowledged for financial support. A. R. Obah Kosso thanks the OGES-Congo for her PhD grant. We warmly thank Vincent Remusat and the Spectropole (http://www.spectropole.fr) for NMR and HRMS analysis. 


\section{Supplementary Material}

Supplementary data associated with this article can be found in the online version

\section{References and notes}

1. Enguehard-Gueiffier, C.; Gueiffier, A. Mini-Rev. Med. Chem. 2007, 7, 888-899.

2. Bagdi, A. K.; Santra, S.; Monir, K.; Alakananda, H. Chem. Commun., 2015, 51, 1555-1575.

3. a) Baquedano, Y.; Moreno, E.; Espuelas, S.; Nguewa, P.; Font M.; Gutierrez, K. J.; Jiménez-Ruiz, A.; Palop, J. A.; Sanmartín, C. Eur. J. Med. Chem. 2014, 74, 116-123. b) Y. Baquedano, V. Alcolea, M. A. Toro, K. J., Gutierrez, P. Nguewa, M. Font, E. Moreno, S. Espuelas, A. Jimenez-Ruiz, J. A. Palop, D. Plano, S. Sanmartín Antimicrob. Agents Chemother. 2016, 60, 3802-3812.

4. a) phenyleneselenocyanate $p$-XSC : Facompre, N. D.; El-Bayoumy, K.; Sun, Y.-W.; Pinto, J. T.; Sinha, R. Cancer Prev. Res. 2010, 3, 975-984. b) For comparison thio/selenocyanate: Sohn, O. S.; Fiala, E. S.; Upadhyaya, P.; Chae, Y. H.; El-Bayoumy, K. Carcinogenesis 1999, $20,615-621$.

5. Krief, A.; Dumont, W.; Delmotte, C. Angew. Chem. Int. Ed. 2000, 39, 1669-1672.

6. Nikolaienko, P.; Rueping, M. Chem. Eur. J. 2016, 22, 2620-2623.

7. Mukherjee, N.; Kundu, D.; Ranu, B. C. Adv. Synth. Catal. 2017, 359, 329-338.

8. Muniraj, N.; Dhineshkumar, J.; Prabhu K. R. ChemistrySelect 2016, 5, 1033-1038.

9. a) V. Nair, A. Augustine, T. G. George, Eur. J. Org. Chem. 2002, 2363-2366. b) Chen, J.; Wang, T.; Wang, T.; Lin, A.; Yao, H.; Xu, J. Org. Chem. Front. 2017, 4, 130-134.

10. Mitra, S.; Ghosh, M., Mishra, S.; Hajra, A. J. Org. Chem. 2015, 80, 8275-8281.

11. Zhang, H.; Wei, Q.; Wei, S.; Qu, J.; Wang, B. Eur. J. Org. Chem. 2016, 20, 3373-3379.

12. Kachanov, A. V.; Slabko, O. Y.; Baranova, O. V.; Shilova, E. V.; Kaminskii. V. A. Tetrahedron Lett. $2004,45,4461-4463$.

13. First synthesis: a) Verneuil, A. Ann. Chim. Phys. 1886, 41, 328-340; crystal data: b) Aksnes O., Foss. O. Acta Chem. Scand. 1954, 1787-1795; c) Hauge, S. Acta Chem. Scand. 1971, 25, 3081-3093; d) Burchell, C. J.; Kilian, P.; Slawin, A. M. Z.; Woollins, J. D.; Tersago, K.; Van Alsenoy, C.; Blockhuys F. Inorg. Chem. 2006, 45, 710-716.

14. a) Castera-Ducros, C.; Paloque, L.; Verhaeghe, P.; Casanova, M.; Cantelli, C.; Hutter, S.; Tanguy, F.; Laget, M.; Remusat, V.; Cohen, A.; Crozet, M. D.; Rathelot, P.; Azas, N.; Vanelle, P. Bioorg. Med. Chem. 2013, 21, 7155-7164; b) Szabo, R.; Crozet, M. D.; Vanelle, P. Heterocycles 2008, 75, 2263-2274; c) Szabo, R.; Crozet, M. D.; Vanelle, P. Synthesis 2008 16, 127-135; d) Crozet, M. D.; Castera-Ducros, C.; Vanelle, P. Tetrahedron Lett. 2006, 47, 7061-7065; e) Castera-Ducros, C.; Crozet, M. D.; Vanelle, P. Heterocycles 2005, 65, 2979-2989. f) Vanelle, P.; Madadi, N.; Roubaud, C.; Maldonado, J.; Crozet, M. D. Tetrahedron 1991, 47, 5173-5184.

15. Kachanov et al. have identified $\mathrm{CO}_{2}$ and $\mathrm{N}_{2}$ gas as by-products from the preparation of triselenodicyanide, see reference 12 .

16. General procedure for the direct selenocyanation of imidazoheterocycles (2a-2r): To a solution of malononitrile (34 mg, $0.52 \mathrm{mmol}, 1 \mathrm{equiv}$.) in DMSO $(0.5 \mathrm{~mL})$ was added $\mathrm{SeO}_{2}\left(174 \mathrm{mg}, 1.57 \mathrm{mmol}, 3\right.$ equiv.) at $25^{\circ} \mathrm{C}$. After $20 \mathrm{~min}$ stirring, 2-phenylimidazo[1,2-a]pyridine 1a $(0.52 \mathrm{mmol}, 1$ equiv.) was added. The reaction mixture was stirred for a further $30 \mathrm{~min}$, then water was added ( $3 \mathrm{~mL})$. The resulting precipitate was filtered off and washed with water $(10 \mathrm{~mL})$. The solid was dried under reduced pressure at $50^{\circ} \mathrm{C}$ to obtain the pure product. Spectral data of selected compounds; compound $2 \mathrm{a}$ : orange solid, $\mathrm{mp} 166^{\circ} \mathrm{C}$; ${ }^{1} \mathrm{H} \mathrm{NMR}\left(250 \mathrm{MHz}, \mathrm{CDCl}_{3}\right) \delta \mathrm{ppm} 8.46(\mathrm{~d}, J=6.7 \mathrm{~Hz}, 1 \mathrm{H}), 7.97(\mathrm{~d}, J=$ $8.0 \mathrm{~Hz}, 2 \mathrm{H}), 7.75(\mathrm{~d}, J=9.0 \mathrm{~Hz}, 1 \mathrm{H}), 7.44-7.55(\mathrm{~m}, 4 \mathrm{H}), 7.14(\mathrm{t}, J=6.7 \mathrm{~Hz}, 1 \mathrm{H}) .{ }^{13} \mathrm{C} \mathrm{NMR}\left(62.5 \mathrm{MHz}, \mathrm{DMSO}-d_{6}\right): \delta \mathrm{ppm} 149.7(\mathrm{C}), 146.6(\mathrm{C}), 132.9$ (C), 128.8, 128.6, 128.5, 127.8, 126.3, $117.0(\mathrm{CH}), 114.2(\mathrm{CH}), 104.3(\mathrm{C}), 99.4(\mathrm{C})$; compound 2b: yellow solid, mp $176^{\circ} \mathrm{C},{ }^{1} \mathrm{H}$ NMR $(400 \mathrm{MHz}$, $\left.\mathrm{CDCl}_{3}\right) \delta \mathrm{ppm} 8.40(\mathrm{~d}, J=7 \mathrm{~Hz}, 1 \mathrm{H}), 7.86(\mathrm{~d}, J=7 \mathrm{~Hz}, 2 \mathrm{H}), 7.70(\mathrm{~d}, J=7,5 \mathrm{~Hz}, 1 \mathrm{H}), 7.42(\mathrm{t}, J=7,5 \mathrm{~Hz}, 1 \mathrm{H}), 7.3(\mathrm{~d}, J=7,9 \mathrm{~Hz}, 2 \mathrm{H}), 7.08(\mathrm{t}, J=7$ $\mathrm{Hz} 1 \mathrm{H}), 2.42(\mathrm{~s}, 3 \mathrm{H}) .{ }^{13} \mathrm{C} \mathrm{NMR}\left(100 \mathrm{MHz}, \mathrm{CDCl}_{3}\right) \delta \mathrm{ppm} 153.2(\mathrm{C}), 148.1(\mathrm{C}), 139.6(\mathrm{CH}), 129.5(\mathrm{CH}), 129.1(\mathrm{CH}), 128.2(\mathrm{CH}), 125.6(\mathrm{CH}), 117.8$ $(\mathrm{CH}), 114.5(\mathrm{CH}), 99.1(\mathrm{C}), 93.8(\mathrm{C}), 21.5\left(\mathrm{CH}_{3}\right)$ ppm. HRMS (ESI): m/z calcd for $\left[\mathrm{C}_{15} \mathrm{H}_{11} \mathrm{~N}_{3} \mathrm{Se}+\mathrm{H}\right]^{+}: 314.0192$, found: 314.0191 .

17. Procedure for the one-pot sequential selenocyanation of 2-phenylimidazo[1,2-a]pyridine: To a solution of 2 -aminopyridine (47 mg, $0.5 \mathrm{mmol})$ in DMSO $(0.25 \mathrm{~mL})$ was added 2-bromo-acetophenone (100 mg, $0.5 \mathrm{mmol}, 1$ equiv.) and potassium carbonate (76 mg, $1.1 \mathrm{equiv}$.). The reaction mixture was stirred at room temperature for $2 \mathrm{~h}$ then a prepared solution of malononitrile $(33 \mathrm{mg}, 0.50 \mathrm{mmol}, 1 \mathrm{equiv}$.) and $\mathrm{SeO}$ ( $166 \mathrm{mg}, 1.49 \mathrm{mmol}, 3$ equiv.) in DMSO $(0.25 \mathrm{~mL})$ was added. The reaction mixture was stirred for a further 30 min, then water was added (13 mL). The aqueous phase was extracted with dichloromethane $(3 \times 10 \mathrm{~mL})$. The combined organic layers were dried on sodium sulfate, filtered and concentrated under reduced pressure. The crude residue was purified by column chromatography on silica gel using dichloromethane:ethyl acetate $=95: 5$ as eluent to afford the pure product 2 a (orange solid, $95 \mathrm{mg}, 63 \%$ yield). 